\title{
Research Article \\ Effect of Ghrelin on Hepatic IGF-Binding Protein-1 Production
}

\author{
Moira S. Lewitt \\ School of Health, Nursing and Midwifery, University of the West of Scotland, Paisley Campus, Paisley PA1 2BE, UK \\ Correspondence should be addressed to Moira S. Lewitt, moira.lewitt@uws.ac.uk
}

Received 28 November 2012; Accepted 1 January 2013

Academic Editors: E. K. Naderali, S. J. Pintauro, and J. Saleh

Copyright (C) 2013 Moira S. Lewitt. This is an open access article distributed under the Creative Commons Attribution License, which permits unrestricted use, distribution, and reproduction in any medium, provided the original work is properly cited.

\begin{abstract}
Ghrelin plays key roles in energy homeostasis by central and peripheral actions that include effects on insulin signalling pathways in liver. Insulin is an important inhibitor of production by hepatocytes of insulin-like growth factor-binding protein-1 (IGFBP-1) which has an endocrine role to inhibit IGF availability. The effects of ghrelin, insulin, an AMPK activator, and an AMPK inhibitor on IGFBP-1 secretion were studied in H4-II-E rat liver cells. Ghrelin $(100 \mathrm{nM})$ blocked the inhibitory effect of a maximally effective concentration of insulin $(10 \mathrm{ng} / \mathrm{mL})$ on IGFBP- 1 secretion during a $5 \mathrm{~h}$ incubation period $(P<0.001)$ in the absence and presence of an AMPK inhibitor. Ghrelin, alone, had no effect on IGFBP-1 production, but enhanced secretion independently of insulin under conditions of AMPK activation $(P<0.001)$. In conclusion, IGFBP-1 is identified as a novel target of ghrelin action in liver that may contribute to its metabolic effects in obesity.
\end{abstract}

\section{Introduction}

Insulin-like growth factor-binding protein-1 (IGFBP-1) is a member of a family of six IGFBPs, which have effects on cell metabolism, motility, growth, and survival via IGFdependent and -independent mechanisms [1]. Liver is the most important source of IGFBP-1 in the human circulation and hepatic $I g f b p 1$ transcription is inhibited by the action of portal insulin [2]. As a consequence, there is an inverse relationship between circulating insulin and IGFBP-1 concentrations $[2,3]$. This relationship is preserved in obesity [4]. In adults with type 2 diabetes, however, there is an upward shift in the regression line so that IGFBP-1 levels are higher than expected for a given insulin concentration [3]. This is consistent with a decrease in hepatic insulin sensitivity or a reduction in hepatic insulin extraction [3], or an increase in factors that stimulate IGFBP-1 directly, including proinflammatory cytokines [5].

Although IGFBP-1 levels in simple obesity are appropriately low for the prevailing hyperinsulinemia, in patients with obesity due to the Prader-Willi syndrome, IGFBP-1 concentrations are not suppressed [6]. Interestingly, circulating levels of the gut peptide ghrelin are also elevated in this syndrome $[7,8]$, whilst they are low in simple obesity [9, 10]. Like IGFBP-1 [11], ghrelin has a glucose counter-regulatory role [12]. Ghrelin is essential for blood glucose control in starvation $[13,14]$. These metabolic effects are mediated in part by a central stimulatory effect of ghrelin on appetite and $\mathrm{GH}$ release and in part by peripheral actions on insulin secretion and insulin sensitivity, and hepatic glucose production $[12,15]$.

We have previously used the insulin-sensitive rat hepatoma cell line H4-II-E to explore the factors regulating IGFBP-1 production. Stimulating AMP-activated protein kinase (AMPK) increases hepatic IGFBP-1 secretion and attenuates the inhibitory effect of insulin [16]. Acylated ghrelin is reported to have a direct effect on intracellular insulin receptor signaling in this cell line [17]. The aim of this study therefore was to determine the short term effect of acylated ghrelin on IGFBP-1 secretion by H4-II-E cells.

\section{Methods}

2.1. Reagents. Acylated ghrelin and 5-aminoimidazole-4carboxamide-ribonucleoside (AICAR) were purchased from Sigma-Aldrich (Sweden). The AMPK inhibitor, 6-3-pyridin-4-yl-pyrrazolo[1,5-a]-pyrimidine (compound C), was from Calbiochem (EMD Biosciences, San Diego, CA), and recombinant human insulin (Actrapid) from Novo-Nordisk (Sweden). 
2.2. Cell Culture. H4-II-E cells, obtained from ATCC (Manassas, VA), were maintained in DMEM, 10\% fetal bovine serum in $5 \% \mathrm{CO}_{2}$ in a humidified incubator, and subcultured at a 1:5 split ratio twice a week. Cells were plated for experiments in 96-place multiwells (Costar, Corning, NY) and made serum-free for $24 \mathrm{~h}$, before experiments were performed on confluent cells in $200 \mu \mathrm{L}$ serum-free medium. Under these conditions 4-7 ng/well IGFBP-1 were secreted during a $5 \mathrm{~h}$ incubation period. Ghrelin, AICAR, and compound $\mathrm{C}$ were stored as concentrated stocks in DMSO. The highest final concentration of DMSO in the cell experiments was $0.1 \%$ which had no effect on IGFBP-1 secretion.

2.3. IGFBP-1 Immunoassay. Rat IGFBP-1 in conditioned medium was measured by immunoassay, as previously described [16]. In brief, rat IGFBP-1 was used as the fixed antigen applied to Immulon 2 plates (Dynex Technologies, Chantilly, VA) competing for rabbit anti-rat IGFBP-1 antibody B4, 1 : 10,000 with rat IGFBP-1 standard or sample containing an unknown concentration of IGFBP-1. After incubation in $100 \mu \mathrm{L}$ assay buffer $(0.1 \mathrm{M}$ sodium phosphate buffer, $0.1 \mathrm{M}$ sodium chloride, $\mathrm{pH} 7.4$, containing $0.1 \%$ Tween (USB, Cleveland, $\mathrm{OH})$ ) for $16 \mathrm{~h}$ at $4^{\circ} \mathrm{C}$ the plates were washed twice with assay buffer and bound antibody detected with goat antirabbit $\gamma$-globulin biotin conjugate (Sigma-Aldrich) followed by neutravidin-horseradish peroxidase conjugate (Pierce, Rockford, IL). After incubation with tetramethylbenzidine free base (Sigma-Aldrich), the reaction was stopped with $2 \mathrm{M}$ sulfuric acid and read spectrophotometrically at $450 \mathrm{~nm}$. The effective assay range was 0.05 to $10 \mathrm{ng}$ /assay well. Over 10 assays, nonspecific binding was $3.9 \pm 0.4 \%$ and half maximal displacement of specifically bound antibody at $0.87 \pm 0.04 \mathrm{ng}$ of rat IGFBP-1 standard. At $0.9 \mathrm{ng} /$ well the between- and within-assay imprecision was $15 \%$ and $4.8 \%$, respectively $(n=$ 10). Samples from one experiment were assayed together using $50 \mu \mathrm{L}$ of medium.

2.4. Statistics. Each experiment presented in this paper was repeated on 3-5 occasions with 3-6 replicates within each experiment for each condition. Data are expressed as a percentage of control, which was set to $100 \%$. Treatment effects were calculated as the percentage of control within each separate experiment. The values shown are the mean \pm SEM for the pooled experiments. Statistical significance, taken as $P<0.01$, was determined by 2 -way analysis of variance followed by a multiple comparisons procedure (Student-Newman-Keuls method).

\section{Results}

The effect of acylated ghrelin on IGFBP-1 secretion was studied in H4-II-E rat liver cells, in the presence and absence of a maximally effective inhibitory concentration of insulin (10 ng/mL). Insulin inhibited IGFBP-1 secretion by H4IIE cells by $60 \%$ during a $5 \mathrm{~h}$ incubation $(P<0.001$, Figure 1$)$. This was partially attenuated by increasing concentrations of ghrelin, so that concentrations of IGFBP-1 were higher in the presence of $100 \mathrm{nM}$ ghrelin and insulin, compared to insulin

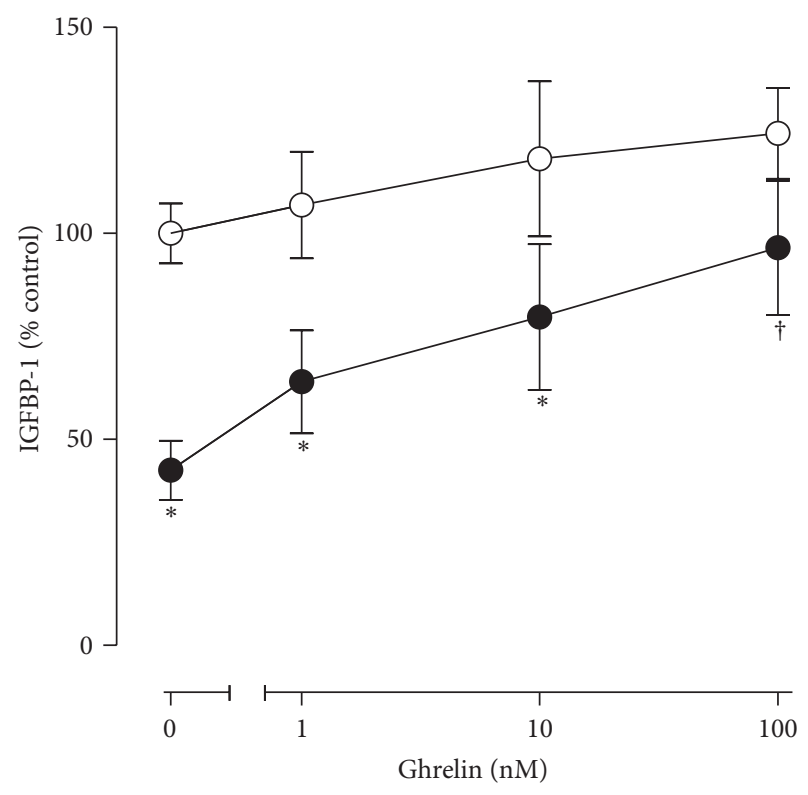

FIGURE 1: The inhibitory effect of insulin on IGFBP-1 secretion by H4-II-E cells is attenuated in the presence of ghrelin. Confluent cells were exposed to increasing concentrations of ghrelin in the absence (open circles) and presence (closed circles) of insulin, for a $5 \mathrm{~h}$ incubation period under serum-free conditions. IGFBP-1 concentrations, measured by specific immunoassay, pooled from three experiments each containing 3-4 replicates per condition, are expressed as a percentage of the secretion by control wells. ${ }^{*} P<$ 0.001 (effect of insulin at a given concentration of ghrelin); ${ }^{\dagger} P<$ 0.001 (effect of ghrelin in the presence of insulin).

alone $(P<0.001)$. In the absence of insulin, ghrelin had no significant effect on IGFBP-1 production.

Compound C $(0.1-100 \mu \mathrm{M})$, a specific inhibitor of AMPK, failed to abolish ghrelin's effect on IGFBP-1 in the presence of insulin (data not shown). Shown in Figure 2, a maximally effective concentration of AICAR $(200 \mu \mathrm{M})$, which activates AMPK, stimulated IGFBP-1 production by $75 \%$ and completely abolished the inhibitory effect of insulin. In the presence of $100 \mathrm{nM}$ ghrelin, the action of AICAR was enhanced $(P<0.001$, compared to AICAR alone). When cells were exposed to ghrelin and AICAR together, insulin inhibited IGFBP-1 production approx 60\% $(P<0.001$, compared to ghrelin and AICAR).

\section{Discussion}

Ghrelin and its receptors have a widespread distribution and multiple peripheral actions. These include effects on liver, where ghrelin is reported to have both insulin-like $[17,18]$ and insulin-opposing actions [17]. It has been shown that ghrelin stimulates proliferation of HepG2 cells through upregulation of the IRS-1-GRB2-MAPK pathway [17]. However it inhibits the IRS-1-PI3 K-Akt pathway, and this is likely to be how it opposes the inhibitory effect of insulin on PEPCK expression [17] and stimulates hepatic glucose production $[17,18]$. It therefore seems likely that this is also the mechanism whereby it blocks the inhibitory effect 


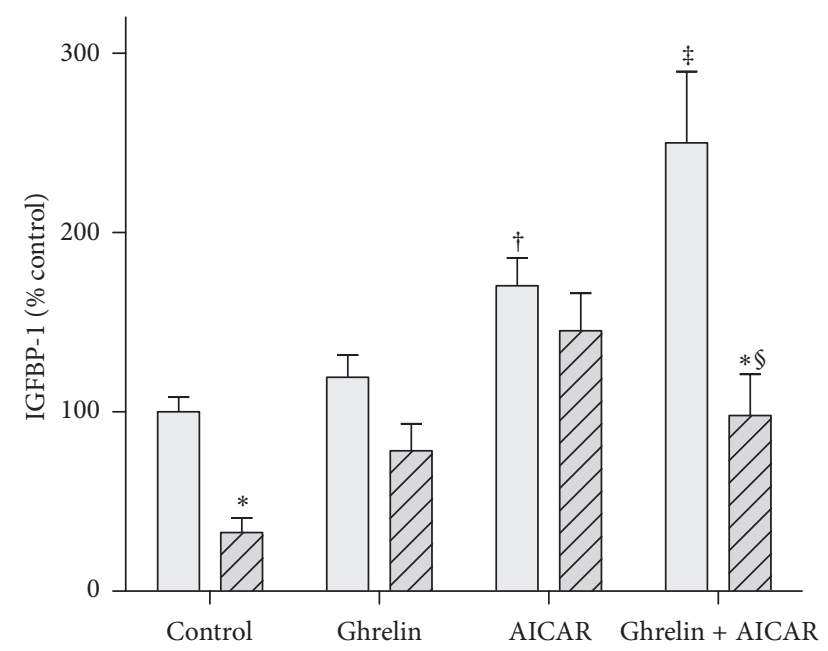

FIGURE 2: Ghrelin enhances the stimulatory effect of AICAR on IGFBP-1 secretion by H4-II-E cells. Confluent cells were exposed to ghrelin $(100 \mathrm{nM})$ and AICAR $(200 \mu \mathrm{M})$ in the absence and presence (hatched bars) of $10 \mathrm{ng} / \mathrm{mL}$ insulin for a $5 \mathrm{~h}$ incubation period under serum-free conditions. IGFBP-1 concentrations, measured by specific immunoassay, pooled from three experiments each containing 4-6 replicates per condition, are expressed as a percentage of the secretion by control wells. ${ }^{*} P<0.001$ (effect of insulin compared to condition in the absence of insulin); ${ }^{\dagger} P<0.001$ (effect of AICAR compared to control wells); ${ }^{\ddagger} P<0.001$ (compared to AICAR alone); ${ }^{\S} P<0.001$ (compared to insulin alone).

of insulin on IGFBP-1 synthesis. Observations of ghrelin's metabolic actions in vitro are supported by the responses observed after ghrelin administration in vivo. Ghrelininduced hyperglycaemia in rats is associated with increased hepatic glucose-6-phosphatase gene expression [19] and with suppressed Akt phosphorylation, reduced phosphorylation of glycogen synthase kinase 3, and an increase in Ppargcla gene expression [20]. In mice, administration of ghrelin prevents suppression of endogenous glucose production by insulin [21].

Since AMPK activity inhibits PEPCK expression, it has been proposed that AMPK inhibition might be a mechanism by which ghrelin stimulates gluconeogenesis [22]. In the studies presented here, the pattern of responses to ghrelin was similar to those previously observed for PEPCK [17]; however the failure of compound $\mathrm{C}$ to abolish the effect of ghrelin on IGFBP-1 in the presence of insulin suggests that the pathways involved in this action are independent of AMPK. I have previously shown that AICAR, an activator of AMPK, in contrast to its inhibitory effect on PEPCK expression, stimulates hepatic IGFBP-1 secretion [16]. I now demonstrate that there is synergism between AICAR and ghrelin in stimulating hepatic IGFBP-1, suggesting that ghrelin has an action downstream of AMPK. Thus, there appear to be two pathways regulating IGFBP-1 production that involve AMPK, one of which is inhibited by insulin. In adults IGFBP-1 is primarily produced in liver, but is also present in deciduum, where it has a paracrine role [23]. In human endometrial stromal cells ghrelin enhances decidualisation, which is reflected in an increase in local
IGFBP-1 production [24]. Direct effects of ghrelin on decidual IGFBP-1 transcription are yet to be explored.

IGFBP-1 and ghrelin appear to have complementary physiological roles. They have similar patterns of nutritional regulation in vivo $[4,6,7,9]$. Like IGFBP-1 $[3,25,26]$, a low fasting ghrelin level is a marker of the metabolic syndrome [27-30]. In Prader-Willi syndrome ghrelin is elevated to levels not explained by relative insulin sensitivity and lower insulin levels [31]. It may be that the relatively high IGFBP1 levels in this syndrome have a similar underlying mechanism. IGFBP-1 and ghrelin both increase blood glucose when administered in pharmacological concentrations, albeit by different mechanisms. The effect of IGFBP-1 on blood glucose is due to it regulation of IGF availability [32], whereas ghrelin has centrally initiated endocrine effects but also has direct effects peripherally, reducing insulin secretion $[12,15]$, shifting fuel utilisation from lipid to carbohydrate thereby inducing adiposity [33] and increasing gluconeogenesis [17, 18]. Antagonists of ghrelin-activated pathways are regarding as promising in the future treatment of obesity and diabetes $[15,34]$.

\section{Conclusion}

These experiments add to knowledge of the complex pathways regulating IGFBP-1. Ghrelin blocks the inhibitory effect of insulin on IGFBP-1 secretion from liver cells and, in the presence of AMPK activation, stimulates IGFBP-1 production. Thus IGFBP-1 is identified as a novel target of ghrelin action in liver that may contribute to the spectrum of metabolic actions of ghrelin in obesity.

\section{Acknowledgments}

The author is grateful to Professor emerita Kerstin Hall (Karolinska Institutet, Sweden) for constructive criticism of the paper, and to the Family Erling-Persson Foundation, Berth von Kantzows Foundation, and Magn. Bergvall's Foundation for their support of these experiments which were carried out during the author's tenure as a researcher in the Department of Molecular Medicine and Surgery, Karolinska Institutet, Stockholm, Sweden.

\section{References}

[1] S. M. Firth and R. C. Baxter, "Cellular actions of the insulin-like growth factor binding proteins," Endocrine Reviews, vol. 23, no. 6, pp. 824-854, 2002.

[2] H. Yki-Järvinen, S. Makimattila, T. Utriainen, and E. M. Rutanen, "Portal insulin concentrations rather than insulin sensitivity regulate serum sex hormone-binding globulin and insulin-like growth factor binding protein 1 in vivo," Journal of Clinical Endocrinology and Metabolism, vol. 80, no. 11, pp. 3227-3232, 1995.

[3] M. S. Lewitt, A. Hilding, C. G. Östenson, S. Efendic, K. Brismar, and K. Hall, "Insulin-like growth factor-binding protein-1 in the prediction and development of type 2 diabetes in middle-aged Swedish men," Diabetologia, vol. 51, no. 7, pp. 1135-1145, 2008.

[4] C. A. Conover, P. D. K. Lee, J. A. Kanaley, J. T. Clarkson, and M. D. Jensen, "Insulin regulation of insulin-like growth factor 
binding protein-1 in obese and nonobese humans," Journal of Clinical Endocrinology and Metabolism, vol. 74, no. 6, pp. 1355-1360, 1992.

[5] C. H. Lang, G. J. Nystrom, and R. A. Frost, "Regulation of IGF binding protein-1 in Hep G2 cells by cytokines and reactive oxygen species," American Journal of Physiology, vol. 276, no. 3, pp. G719-G727, 1999.

[6] C. Höybye, J. Frystyk, and M. Thorén, “The growth hormoneinsulin-like growth factor axis in adult patients with Prader Willi syndrome," Growth Hormone and IGF Research, vol. 13, no. 5, pp. 269-274, 2003.

[7] D. E. Cummings, K. Clement, J. Q. Purnell et al., "Elevated plasma ghrelin levels in Prader-Willi syndrome," Nature Medicine, vol. 8, no. 7, pp. 643-644, 2002.

[8] A. Delparigi, M. Tschöp, M. L. Heiman et al., "High circulating ghrelin: a potential cause for hyperphagia and obesity in Prader-Willi syndrome," Journal of Clinical Endocrinology and Metabolism, vol. 87, no. 12, pp. 5461-5464, 2002.

[9] M. Tschöp, C. Weyer, P. A. Tataranni, V. Devanarayan, E. Ravussin, and M. L. Heiman, "Circulating ghrelin levels are decreased in human obesity," Diabetes, vol. 50, no. 4, pp. 707-709, 2001.

[10] T. Shiiya, M. Nakazato, M. Mizuta et al., "Plasma ghrelin levels in lean and obese humans and the effect of glucose on ghrelin secretion," Journal of Clinical Endocrinology and Metabolism, vol. 87, no. 1, pp. 240-244, 2002.

[11] M. S. Lewitt and R. C. Baxter, "Insulin-like growth factor-binding protein-1: a role in glucose counterregulation?" Molecular and Cellular Endocrinology, vol. 79, no. 1-3, pp. C147-C152, 1991.

[12] P. J. Delhanty and A. J. van der Lely, "Ghrelin and glucose homeostasis," Peptides, vol. 32, no. 11, pp. 2309-2318, 2011.

[13] T. J. Zhao, G. Liang, R. L. Li et al., "Ghrelin O-acyltransferase (GOAT) is essential for growth hormone-mediated survival of calorie-restricted mice," Proceedings of the National Academy of Sciences of the United States of America, vol. 107, no. 16, pp. 7467-7472, 2010.

[14] Y. Sun, N. F. Butte, J. M. Garcia, and R. G. Smith, "Characterization of adult ghrelin and ghrelin receptor knockout mice under positive and negative energy balance," Endocrinology, vol. 149, no. 2, pp. 843-850, 2008.

[15] P. J. Verhulst and I. Depoortere, "Ghrelin's second life: from appetite stimulator to glucose regulator," World Journal of Gastroenterology, vol. 18, no. 25, pp. 3183-3195, 2012.

[16] M. S. Lewitt, "Stimulation of IGF-binding protein-1 secretion by AMP-activated protein kinase," Biochemical and Biophysical Research Communications, vol. 282, no. 5, pp. 1126-1131, 2001.

[17] M. Murata, Y. Okimura, K. Iida et al., "Ghrelin modulates the downstream molecules of insulin signaling in hepatoma cells," The Journal of Biological Chemistry, vol. 277, no. 7, pp. 5667-5674, 2002.

[18] C. Gauna, P. J. D. Delhanty, L. J. Hofland et al., "Ghrelin stimulates, whereas des-octanoyl ghrelin inhibits, glucose output by primary hepatocytes," Journal of Clinical Endocrinology and Metabolism, vol. 90, no. 2, pp. 1055-1060, 2005.

[19] R. Barazzoni, A. Bosutti, M. Stebel et al., "Ghrelin regulates mitochondrial-lipid metabolism gene expression and tissue fat distribution in liver and skeletal muscle," American Journal of Physiology, vol. 288, no. 1, pp. E228-E235, 2005.

[20] R. Barazzoni, M. Zanetti, M. R. Cattin et al., "Ghrelin enhances in vivo skeletal muscle but not liver AKT signaling in rats," Obesity, vol. 15, no. 11, pp. 2614-2623, 2007.
[21] A. C. Heijboer, A. M. van den Hoek, E. T. Parlevliet et al., "Ghrelin differentially affects hepatic and peripheral insulin sensitivity in mice," Diabetologia, vol. 49, no. 4, pp. 732-738, 2006.

[22] B. Xue and B. B. Kahn, "AMPK integrates nutrient and hormonal signals to regulate food intake and energy balance through effects in the hypothalamus and peripheral tissues," Journal of Physiology, vol. 574, no. 1, pp. 73-83, 2006.

[23] M. Westwood, "Role of insulin-like growth factor binding protein 1 in human pregnancy," Reviews of Reproduction, vol. 4, no. 3, pp. 160-167, 1999.

[24] N. Tawadros, L. A. Salamonsen, E. Dimitriadis, and C. Chen, "Facilitation of decidualization by locally produced ghrelin in the human endometrium," Molecular Human Reproduction, vol. 13, no. 7, pp. 483-489, 2007.

[25] M. S. Lewitt, A. Hilding, K. Brismar, S. Efendic, C. G. Östenson, and K. Hall, "IGF-binding protein 1 and abdominal obesity in the development of type 2 diabetes in women," European Journal of Endocrinology, vol. 163, no. 2, pp. 233-242, 2010.

[26] S. N. Rajpathak, M. He, Q. Sun et al., "Insulin-like growth factor axis and risk of type 2 diabetes in women," Diabetes, vol. 61, no. 9, pp. 2248-2254, 2012.

[27] O. Ukkola, S. M. Pöykkö, and Y. A. Kesäniemi, "Low plasma ghrelin concentration is an indicator of the metabolic syndrome," Annals of Medicine, vol. 38, no. 4, pp. 274-279, 2006.

[28] A. Ikezaki, H. Hosoda, K. Ito et al., "Fasting plasma ghrelin levels are negatively correlated with insulin resistance and PAI1 , but not with leptin, in obese children and adolescents," Diabetes, vol. 51, no. 12, pp. 3408-3411, 2002.

[29] A. Katsuki, H. Urakawa, E. C. Gabazza et al., "Circulating levels of active ghrelin is associated with abdominal adiposity, hyperinsulinemia and insulin resistance in patients with type 2 diabetes mellitus," European Journal of Endocrinology, vol. 151, no. 5, pp. 573-577, 2004.

[30] S. M. Pöykkö, E. Kellokoski, S. Hörkkö, H. Kauma, Y. A. Kesäniemi, and O. Ukkola, "Low plasma ghrelin is associated with insulin resistance, hypertension, and the prevalence of type 2 diabetes," Diabetes, vol. 52, no. 10, pp. 2546-2553, 2003.

[31] A. P. Goldstone, M. Patterson, N. Kalingag et al., "Fasting and postprandial hyperghrelinemia in Prader-Willi syndrome is partially explained by hypoinsulinemia, and is not due to peptide YY 3-36 deficiency or seen in hypothalamic obesity due to craniopharyngioma," Journal of Clinical Endocrinology and Metabolism, vol. 90, no. 5, pp. 2681-2690, 2005.

[32] L. J. Murphy, "The role of the insulin-like growth factors and their binding proteins in glucose homeostasis," Experimental Diabesity Research, vol. 4, no. 4, pp. 213-224, 2003.

[33] M. Tschop, D. L. Smiley, and M. L. Heiman, "Ghrelin induces adiposity in rodents," Nature, vol. 407, no. 6806, pp. 908-913, 2000.

[34] M. Patterson, S. R. Bloom, and J. V. Gardiner, "Ghrelin and appetite control in humans-potential application in the treatment of obesity," Peptides, vol. 32, no. 11, pp. 2290-2294, 2011. 


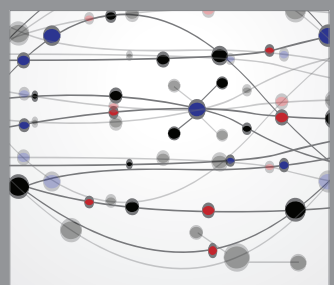

The Scientific World Journal
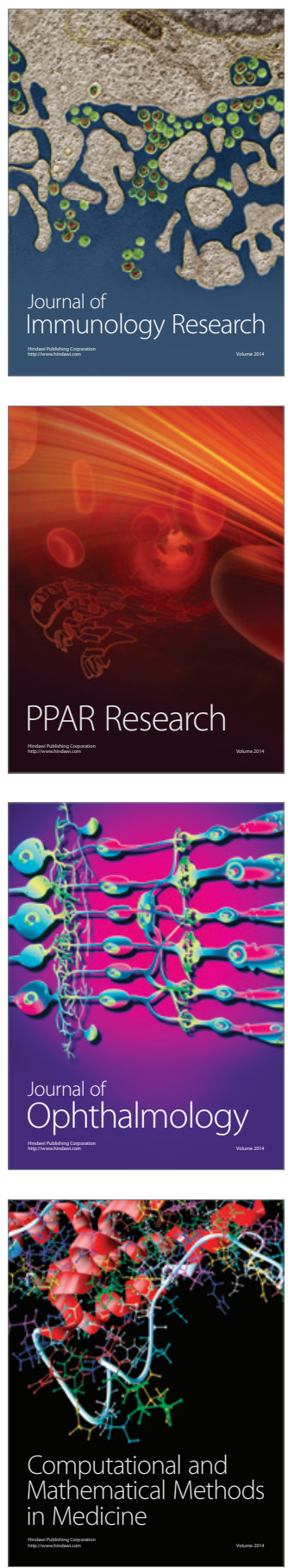

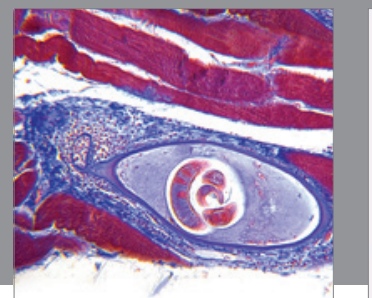

Gastroenterology

Research and Practice
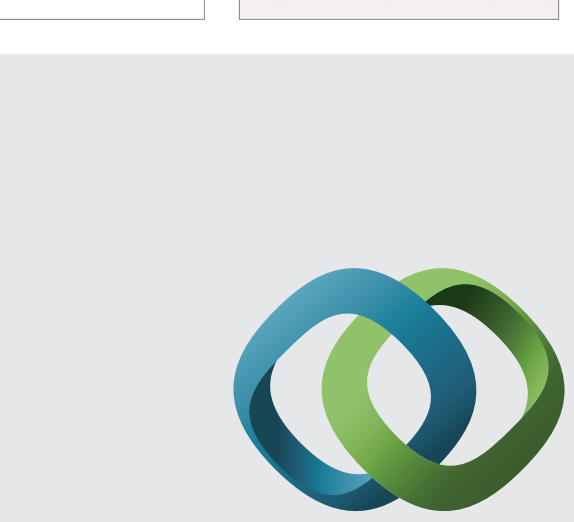

\section{Hindawi}

Submit your manuscripts at

http://www.hindawi.com
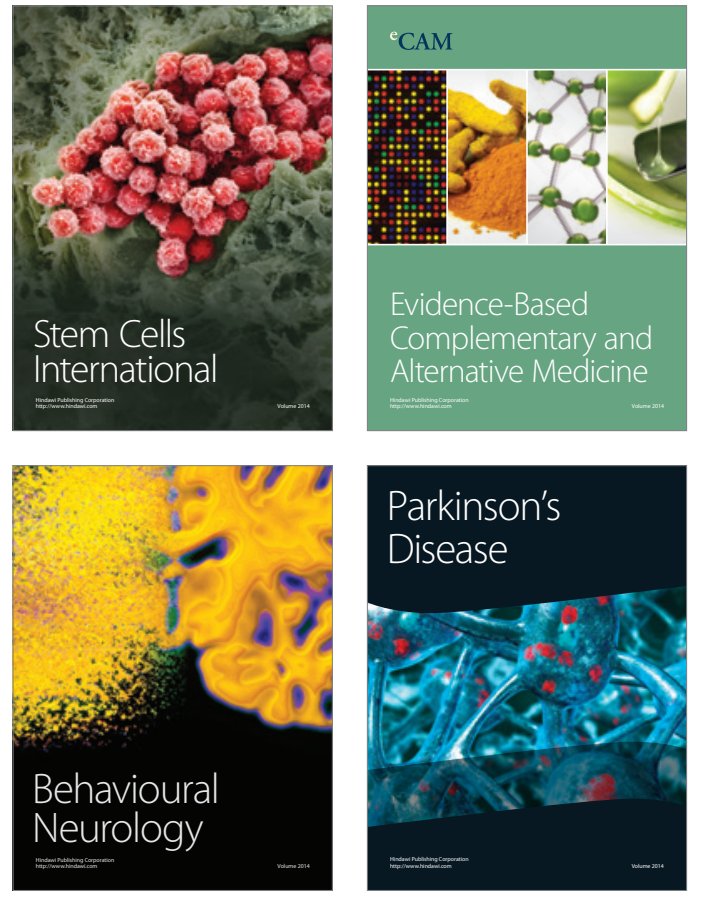
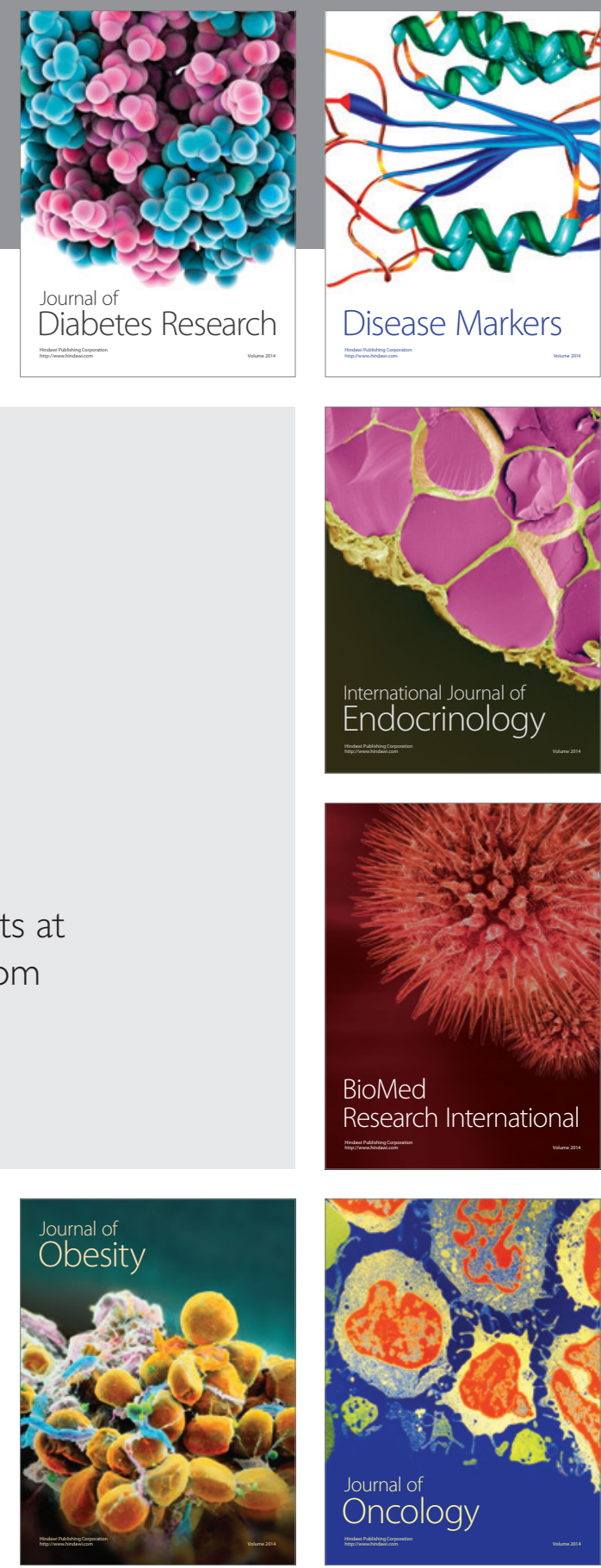

Disease Markers
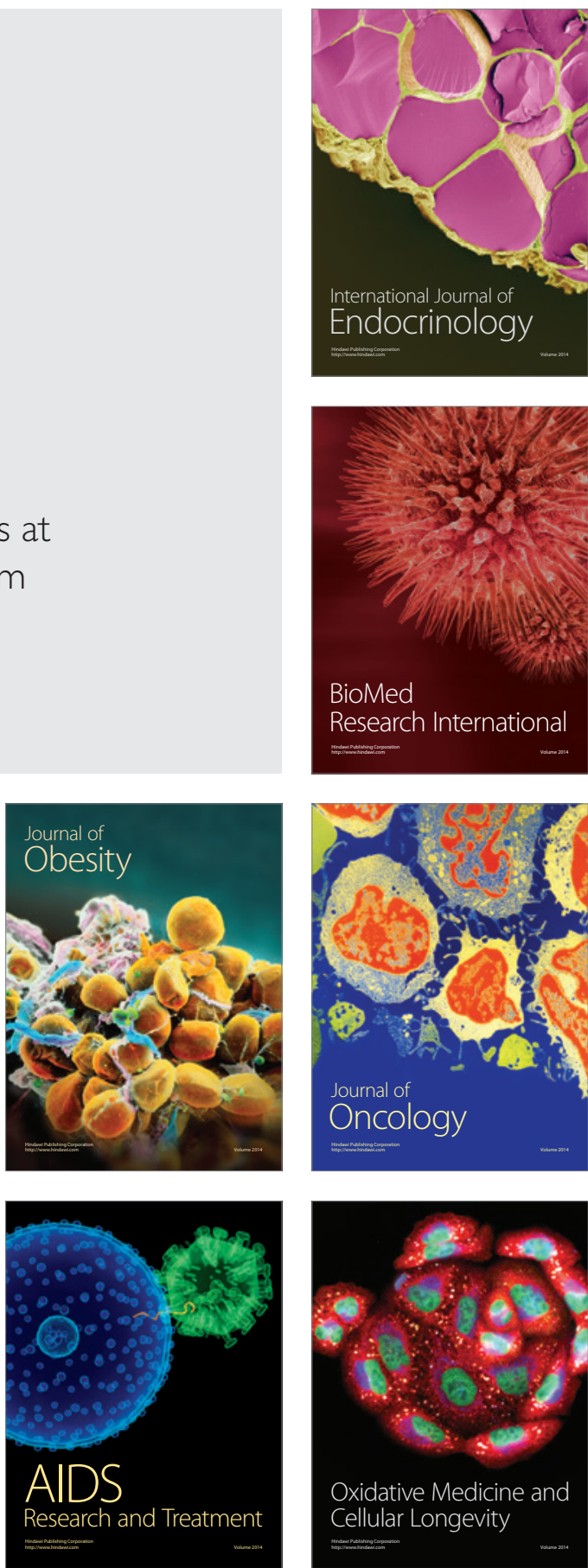